\title{
IMPORTÂNCIA DOS SERVIÇOS TOPOGRÁFICOS PARA A IMPLANTAÇÃO, OPERAÇÃO E MONITORAMENTO DE ATERROS SANITÁRIOS
}

Ana Paula Miranda Pereira - anapaulapmirandap@gmail.com Universidade Federal de Minas Gerais (UFMG)

Bruno Dias Martins da Costa - brunodiasmc@gmail.com Centro Federal de Educação Tecnológica de Minas Gerais (CEFET/MG)

Pedro Mendes Xavier - pmxavier@outlook.com Universidade Federal de Minas Gerais (UFMG)

Cícero Antonio Antunes Catapreta - catapret@pbh.gov.br Superintendência de Limpeza Urbana de Belo Horizonte/MG

Gustavo Ferreira Simões - gustavo@desa.ufmg.br

Universidade Federal de Minas Gerais (UFMG) 


\section{RESUMO}

Da mesma forma que em qualquer projeto de obras de infraestrutura, o emprego dos serviços topográficos em áreas de disposição final de resíduos sólidos urbanos (aterros sanitários) é de grande importância e se destaca por ser necessário em todas as etapas de gerenciamento dessas unidades, desde a seleção de áreas para implantação, durante as fases de implantação, operação e manutenção, até a etapa de monitoramento. Nesse sentido, esse trabalho tem como finalidade apresentar e descrever os principais usos dos serviços topográficos nas atividades de implantação, operação e monitoramento dessas unidades, destacando a sua importância e pontuando algumas particularidades. $\mathrm{O}$ trabalho apresenta alguns resultados referentes ao aterro sanitário de Belo Horizonte (MG), um dos maiores do Brasil. Embora o foco da discussão sejam os aterros de grande porte, onde os serviços de topografia são devem ser realizados de forma intensa e permanente, ressalta-se que os serviços topográficos são indispensáveis também em aterros de médio e pequeno portes.

Palavras-chave: Aterro Sanitário, Resíduos Sólidos, Topografia, Monitoramento.

\section{INTRODUÇÃO}

A disposição de resíduos sólidos urbanos (RSU) de forma inadequada pode gerar diversos impactos ambientais e sociais, principalmente em relação à poluição do solo, do ar e de recursos hídricos. Muitos pesquisadores têm abordado temas diversos a respeito do manejo dos resíduos sólidos urbanos, em especial o tratamento e a disposição final em aterros sanitários, que representam um dos maiores problemas enfrentados pelas cidades brasileiras em termos de saneamento ambiental (CATAPRETA et al., 2007).

Todas as obras de infraestrutura demandam a permanente realização de serviços de topografia, em todas as suas etapas. No caso dos aterros sanitários, além dos serviços usuais relacionados à locação de elementos de projeto, observa-se a necessidade de realização de diversas outras atividades relacionadas aos serviços topográficos, pois se trata de uma estrutura que é construída em etapas e que apresenta particularidades no comportamento geomecânico dos RSU dispostos, tornando-a extremamente deformável.

Neste contexto, destaca-se a necessidade de realização de programas de monitoramento. Observa-se no Brasil que um número crescente de aterros sanitários 


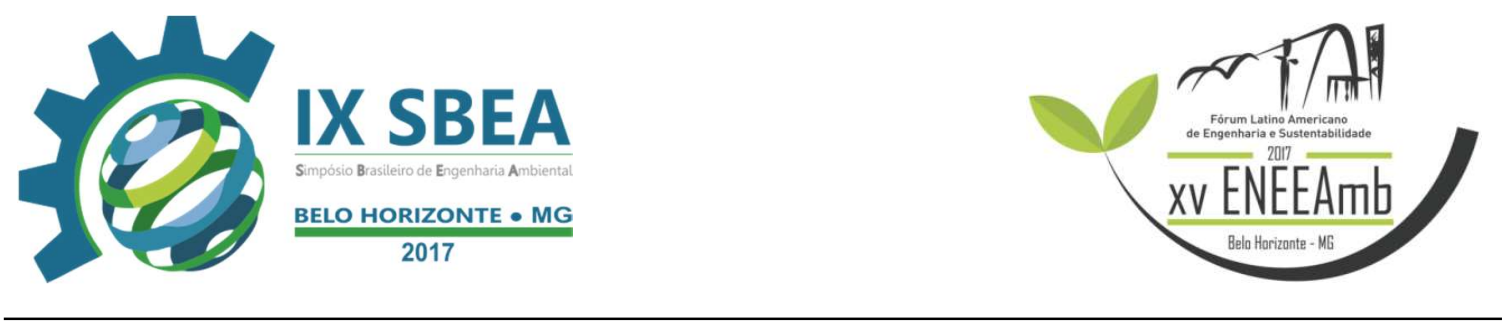

possui programas de monitoramento ambiental e geotécnico, denotando a necessidade de se despender uma maior atenção ao controle dos impactos gerados nesses empreendimentos. Em menor escala, observa-se também a realização do chamado monitoramento operacional, que é realizado durante as etapas de enchimento dos aterros.

Os principais objetivos dos programas de monitoramento executados nos aterros sanitários são acompanhar continuamente o comportamento geomecânico e o desempenho ambiental destes, de forma a permitir a identificação, em tempo hábil, de alterações no padrão de comportamento previsto e a proposição de medidas preventivas e corretivas, orientando os trabalhos de conservação e manutenção. A sistemática do monitoramento geotécnico dos aterros deve ser prevista a fim de permitir o adequado acompanhamento das condições de estabilidade estrutural do maciço de resíduos, tanto em termos de recalque e deslocamentos como geração e variabilidade das pressões internas de gases e lixiviados.

Um importante aspecto, necessário à execução desses monitoramentos, e que muitas vezes é colocado em segundo plano, está relacionado às formas de obtenção de dados, os quais devem ser confiáveis e precisos, possibilitando uma avaliação contínua e adequada dos registros. Nesse sentido, pode-se destacar a obtenção de dados por meio de levantamentos e registros topográficos.

O uso da topografia no processo de monitoramento de aterros sanitários é aplicável, frequentemente, em diversos acompanhamentos que são realizados ao longo da vida útil destes, incluindo as fases de planejamento, projeto, implantação, operação e descomissionamento.

A realização dos serviços topográficos nos programas de monitoramento pressupõe: observações de alta precisão; repetibilidade das observações; integração entre observações de diferentes tipos, obtidas a partir de diferentes equipamentos, e análise criteriosa dos registros.

As tecnologias utilizadas no processo de monitoramento de aterros sanitários variam de acordo com o porte do aterro, incluindo aspectos técnicos e de custos dos serviços. Atualmente o mercado dispõe de estações totais com grande precisão, estações totais robotizadas, receptores GNSS (Global Navigation Satellite System), RTK (Real Time Kinematic), níveis de altíssima precisão, além de escaneamento a laser. 


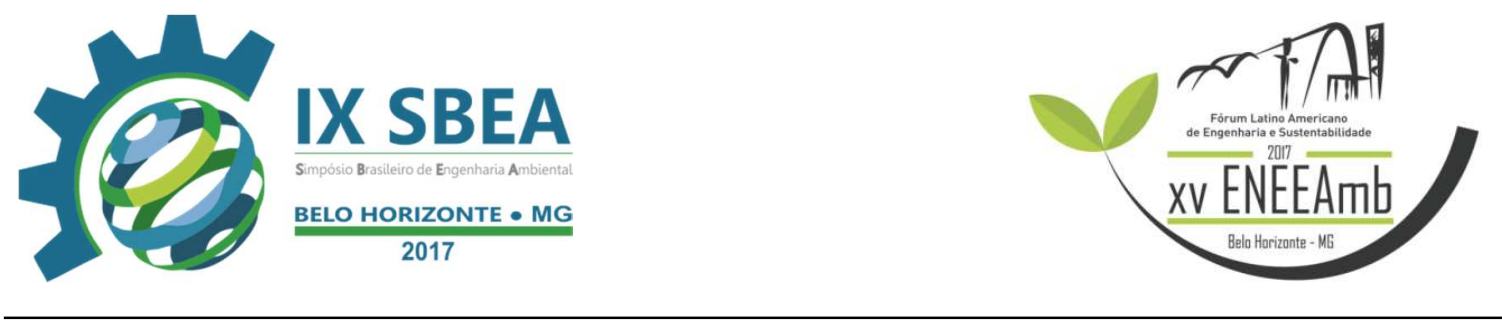

O presente trabalho tem como objetivo demonstrar a necessidade e importância da utilização contínua de serviços topográficos em todas as fases dos aterros sanitários, com destaque para as atividades relacionadas ao monitoramento.

\section{METODOLOGIA}

O trabalho envolveu uma pesquisa qualitativa, na qual se buscou avaliar o emprego e a importância dos levantamentos de dados por meio de topografia, em todas as etapas de projeto, implantação e operação de um aterro sanitário, tendo como estudo de caso as atividades que foram e vêm sendo realizados pela equipe de agrimensura responsável pelos serviços topográficos realizados do aterro sanitário de Belo Horizonte (MG).

\section{RESULTADOS}

O acompanhamento topográfico de um aterro sanitário envolve todas as fases de execução desses empreendimentos: escolha da área, projeto, implantação, operação, monitoramento, incluindo a etapa pós-fechamento. São apresentados a seguir exemplos de atividades onde a realização dos serviços de topografia está presente, sendo destacados também aspectos que comprovam a importância desses serviços.

\subsection{Seleção da Área para Implantação do Aterro Sanitário}

Como em qualquer projeto de empreendimentos de infraestrutura, nesta fase, os serviços topográficos se mostram necessários, pois fornecerão a base para o entendimento do relevo e informações importantes sobre a rede de drenagem natural (cursos e corpos de água). Ainda sem o nível de detalhe exigido na etapa de desenvolvimento do projeto executivo, os resultados em termos de mapas topográficos podem auxiliar na identificação do melhor método de operação, de acordo com o porte do aterro sanitário em estudo e a declividade das áreas em avaliação.

A execução dos aterros pode ser feita pelos seguintes métodos: a) trincheira; b) área ou superfície; c) rampa, encosta ou depressão. Áreas onde o levantamento topográfico preliminar indicar baixas declividades (áreas planas) mostram-se mais adequadas ao método da trincheira ou da área, dependendo do porte do aterro a ser 


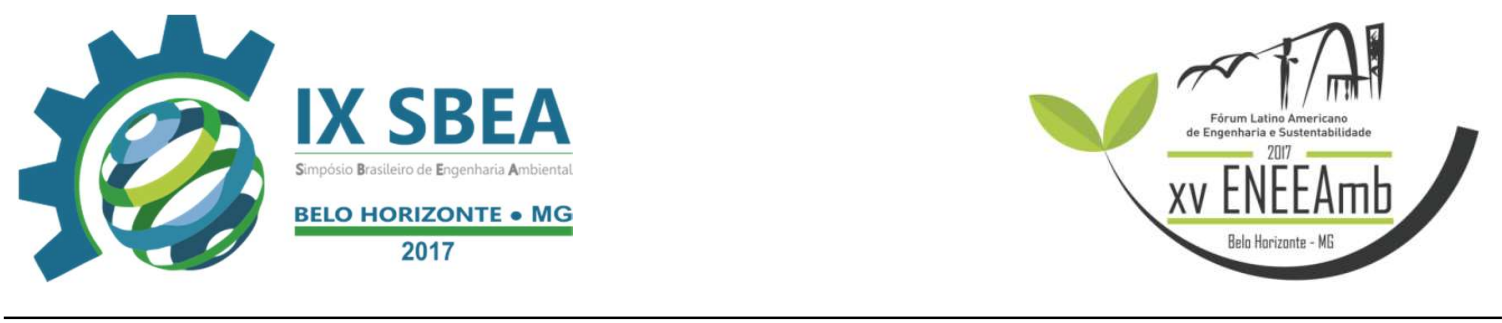

implantado. Em áreas com declividade mais acentuadas, podem ser empregados os métodos de encosta ou depressão.

Segundo Lima e Guimarães (2001), os dados topográficos obtidos nessa etapa, são informações sobre a compartimentação geomorfológica e características das unidades que compõem o relevo (colinas, encostas, talvegues etc.) e sobre declividade dos terrenos. É um dos fatores mais relevantes na escolha do local, pois há uma relação muito grande entre o relevo e a ampliação dos problemas ambientais.

Nessa fase de seleção de áreas para implantação do aterro sanitário, o levantamento planialtimétrico é feito sem nenhuma intervenção nas áreas em avaliação para implantação do projeto. Além dos fatores mencionados serem importantes para análise econômica, eles também devem ser considerados para a análise geotécnica da área. Embora não tenha essa finalidade, a realização dos levantamentos topográficos preliminares das áreas em avaliação pode levar à identificação preliminar dos tipos de solos existentes na região e a existência de materiais rochosos.

\subsection{Projeto do Aterro Sanitário}

Escolhida a área, deve-se fazer o levantamento topográfico desta em escala de detalhe adequada, devendo incluir, no mínimo o cadastramento contendo todos os elementos físicos presentes na área e utilizando as convenções preconizadas pela ABNT.

Ao final, deverá ser elaborada planta planialtimétrica em escala adequada contendo as curvas de nível, com equidistância máxima, geralmente, de $100 \mathrm{~cm}$ (ou outra de acordo com as normas técnicas) e com indicação das referências de nível (RN), bem como indicando a poligonal do terreno objeto do levantamento, com a sequência de vértices de coordenadas, implantados através de medidas de distâncias e ângulos, realizadas com métodos e critérios que garantam uma precisão compatível com a natureza dos trabalhos.

Com o levantamento topográfico e a definição das áreas propriamente ditas para a disposição dos resíduos, pode-se definir o layout da área selecionada, locando todos as unidades componentes do aterro sanitário, ou de forma mais ampla, da central de tratamento e disposição final de resíduos sólidos.

A Figura 1 apresenta a planta topográfica da área destinada à implantação do 


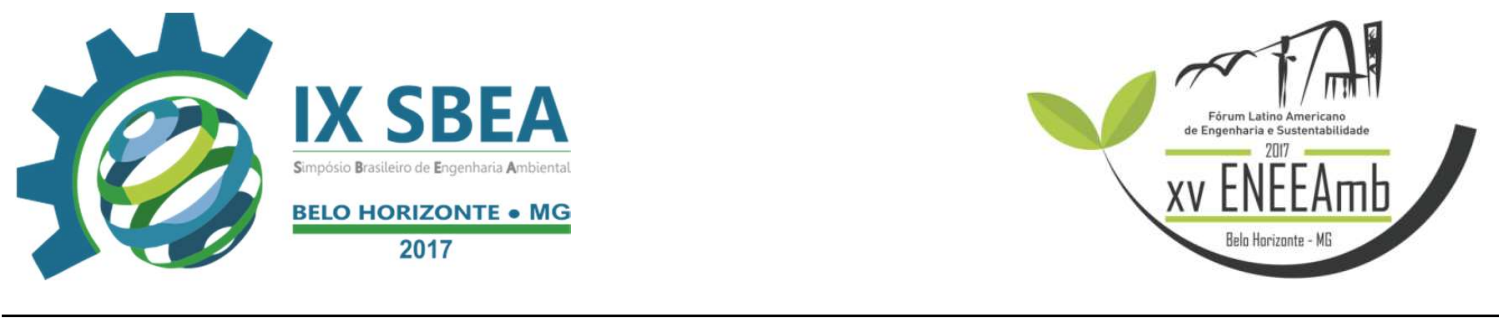

aterro sanitário, localizado na BR-040 de Belo Horizonte (MG), realizado em 1974. Observa-se que o terreno possui características condizentes com sua finalidade, com depressões, praticamente fechadas. Na Figura 2, é apresentado o projeto geométrico inicial desse aterro, baseado no levantamento topográfico da área.
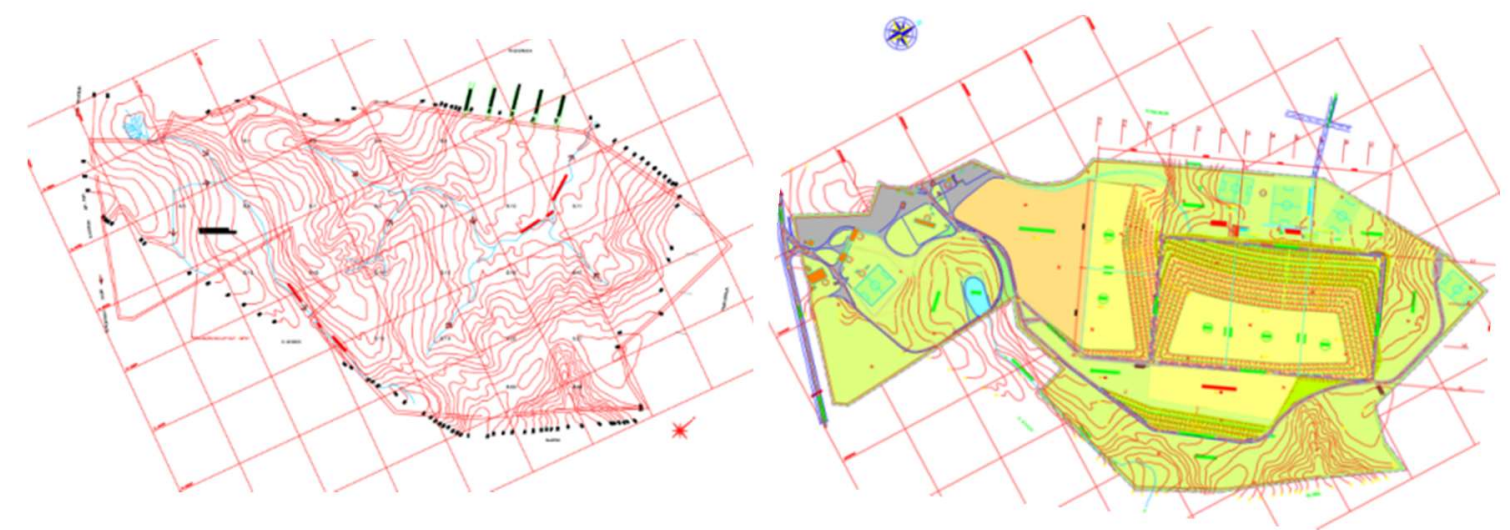

Figura 1 - Levantamento topográfico Figura 2 - Projeto geométrico do aterro original da área do aterro sanitário de Belo sanitário de Belo Horizonte baseado no Horizonte (MG).

levantamento topográfico.

Nessa etapa, o estudo da área é mais aprofundado a fim de identificar com maior precisão os possíveis impactos negativos. É obtido um conjunto de informações tais como, informações sobre o relevo, declividade dos terrenos e características dos solos, estas a partir de um detalhado programa de investigações geotécnicas de campo de laboratório. A partir dessas informações e da planta topográfica, é possível desenvolver o projeto geométrico do aterro sanitário, que deve ser elaborado considerando principalmente os seguintes aspectos: a) garantia da segurança estrutural, em termos da estabilidade dos taludes; b) atendimento à vida útil exigida; c) questões econômicas, principalmente a adequação do método utilizado ao porte do empreendimento. Esse projeto deve ser apresentado em planta e perfil, com os alteamentos do aterro sanitário, indicando a inclinação dos taludes, larguras das bermas e altura de cada alteamento.

\subsection{Implantação do Aterro Sanitário}

Os serviços topográficos a serem realizados nesta etapa envolvem a execução de serviços gerais de topografia de precisão, necessários tanto para a locação das diversas unidades e componentes físicos que compõem o empreendimento, definidos na etapa de 


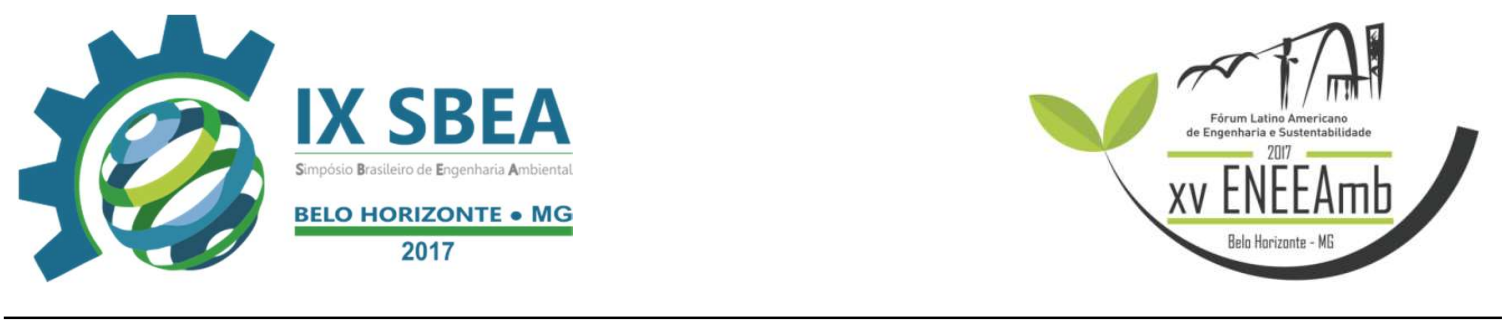

projeto, quanto para o monitoramento contínuo do desempenho do aterro sanitário, inclusive após o encerramento de sua vida útil. Deve assegurar, ainda, a perfeita fidelidade às recomendações do projeto executivo, particularmente no que se refere à forma e à declividade da superfície final do aterro e locação (alinhamentos, declividades e caimentos) de todos os componentes dos sistemas de drenagem (pluvial, líquidos lixiviados e de gases).

\subsection{Operação do Aterro Sanitário}

De forma semelhante à etapa de implantação, durante a operação dos aterros sanitários, os serviços de topografia são indispensáveis, pois se trata de um empreendimento que será construído em etapas e que deve ser objeto de acompanhamento constante, de modo a garantir que os detalhes de projeto e o manual operacional sejam seguidos de forma adequada.

Essa construção em etapas, associada às grandes movimentações (recalques) observadas nesses empreendimentos, exigem ajustes constantes no projeto executivo, que só é conseguida com a permanente realização de serviços topográficos. Como exemplos, podem ser citadas a necessidade de relocação, redirecionamento e/ou introdução de novos dispositivos de drenagem superficial e a correção de cotas dos diversos alteamentos das células de disposição de resíduos.

Embora ainda incipiente no Brasil, destaca-se a importância de realização do chamado monitoramento operacional, que visa garantir que hipóteses de projeto e procedimentos operacionais prescritos no manual de operação, estejam sendo obtidos. Como exemplo de itens que devem ser monitorados nesta etapa, e que envolve os serviços topográficos, merecem destaque a densidade dos resíduos aterrados e compactados e a inclinação da rampa de aterragem.

\subsubsection{Densidade dos resíduos aterrados e compactados}

A densidade dos resíduos após a compactação é um parâmetro utilizado em diversos momentos na etapa de projeto, principalmente na avaliação da vida útil e nas análises de estabilidade estrutural dos aterros sanitários. Desta forma, o acompanhamento da densidade dos resíduos compactados permite avaliar se os valores utilizados em 


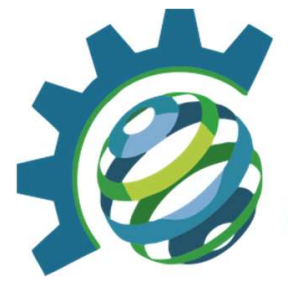

projeto estão sendo obtidos e caso não estejam, permite que sejam tomadas medidas corretivas, tanto na operação (por exemplo, melhoria na compactação), quanto na eventual alteração do projeto geométrico, de modo a garantir as condições de estabilidade requeridas.

Esse controle deve ser realizado pelo registro topográfico do avanço das frentes de serviços (Figuras 3 e 4) associado à pesagem dos veículos nas balanças do aterro sanitário.

No aterro sanitário de Belo Horizonte ( $\mathrm{MG})$, este monitoramento foi realizado durante 12 anos e com frequência diária. Em aterros de médio e pequeno porte, essa frequência pode ser diminuída. Observa-se a necessidade e a importância da presença das equipes de topografia durante todo o enchimento do aterro sanitário.

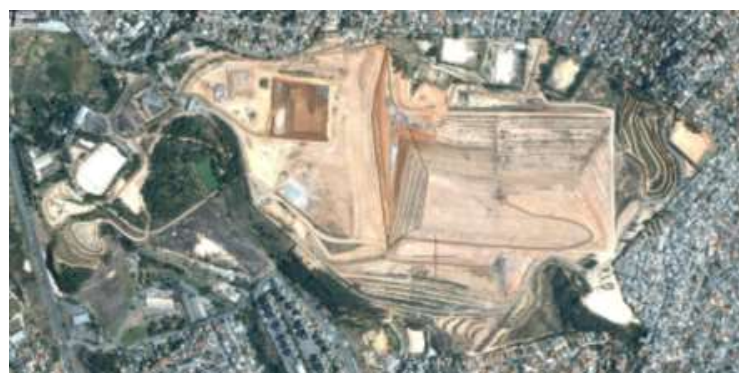

Figura 3 - Aterragem de RSU no aterro sanitário de Belo Horizonte (MG)

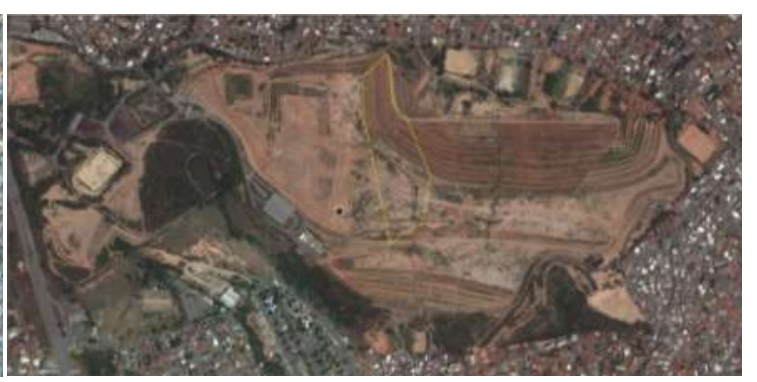

Figura 4 - Levantamento do volume aterrado após a conclusão da operação de aterragem de RSU.

\subsubsection{Inclinação das rampas de aterragem}

A compactação dos RSU pode ser influenciada por diversos fatores, tais como: características dos RSU (composição e teor de umidade) e características operacionais (inclinação da rampa de compactação, espessura da camada de resíduos, numero de passadas e tipo de equipamento utilizado).

Usualmente a compactação dos RSU é realizada em rampa, com os equipamentos compactadores operando no sentido ascendente. A medição ou aferição da rampa de compactação dos RSU (inclinação da rampa de aterragem) deve realizada pela equipe de topografia. Embora a literatura e a experiência de operadores de aterros recomendem a compactação em rampas pré-definidas, a análise conjunta dos valores das densidades e das rampas, obtidos nas condições reais de campo, permite o estabelecimento das melhores condições de compactação, confirmando mais uma vez a importância da 


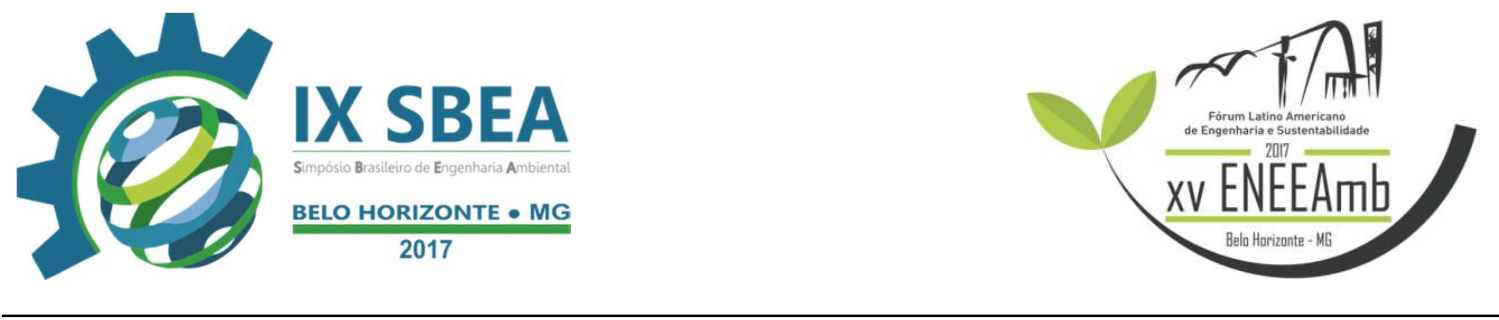

realização desses monitoramentos e da presença de equipes de topografia durante a operação dos aterros sanitários. Na Figura 5 pode ser observada a realização desses serviços durante a aterragem de RSU no aterro sanitário de Belo Horizonte.

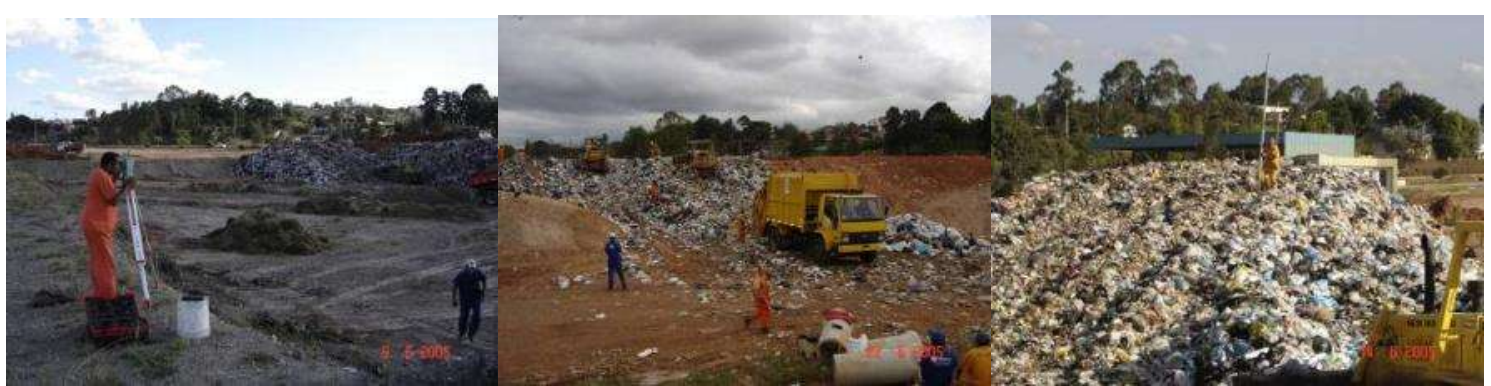

Figura 5 - Registro da inclinação da rampa de aterragem (Fonte: CATAPRETA, 2008)

\subsection{Monitoramento de Movimentações Verticais e Horizontais}

Os resíduos sólidos urbanos são materiais extremamente compressíveis, que podem apresentar significativas movimentações ao longo do tempo. Os impactos dessas movimentações têm reflexo em diversos aspectos, principalmente na vida útil e na estabilidade estrutural dos taludes das células de disposição, além das consequências na operação, com relação aos dispositivos do sistema de drenagem superficial.

Nas etapas de operação e pós-fechamento de um aterro sanitário deve-se realizar de forma regular o monitoramento geotécnico do maciço, que consiste no acompanhamento das movimentações verticais (recalques) e horizontais, na superfície e no interior do aterro, além das condições de poro-pressão, que não são objeto deste trabalho. Essas movimentações podem ser medidas com a utilização de medidores de recalque superficiais e com o uso de inclinômetros, para os registros em profundidade. Todos esses controles são resultado de contínuos levantamentos topográficos realizados durante e a após a construção dos aterros sanitários.

O monitoramento de recalques em aterros sanitários exige a definição de um benchmark, ou seja, um ponto de referência fixo situado no terreno natural. A partir dessa referência, medidores de recalques superficiais, instalados na superfície final do aterro devem ser monitorados por nivelamento geométrico de superfície, por meio dos serviços topográficos. Tanto os movimentos horizontais quanto os verticais desses medidores devem ser monitorados com frequência adequada, de acordo com a análise da evolução dos recalques. Esse monitoramento permite atualizar continuamente a capacidade real do 


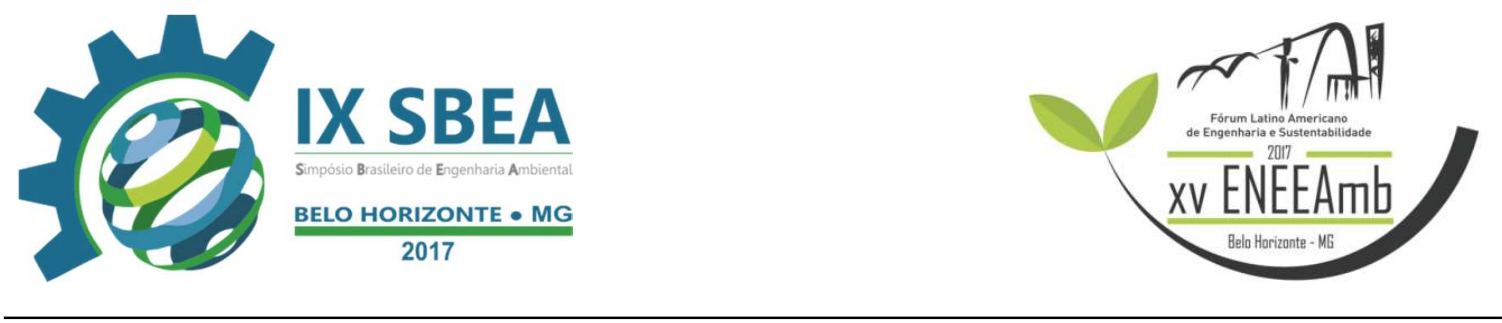

aterro, fornecendo informações contínuas sobre a sua vida útil, o que se figura como uma importante informação para o planejamento.

Essa permanente alteração da geometria, ocasionada pelos contínuos recalques dos aterros sanitários, exige que sejam realizadas regularmente análises de estabilidade dos taludes, que tem como principais informações de entrada a geometria do aterro, as propriedades dos resíduos e demais materiais utilizados, além das condições de poropressões nos líquidos e gases. Neste contexto, a realização de levantamentos topográficos regulares coloca-se como ferramenta de extrema importância. Associa-se a isso a exigência legal de elaboração de planos de desenvolvimento futuro da área após a estabilidade física.

Além do usual registro dos recalques verticais, a análise da evolução das movimentações em perfil permite uma avaliação mais completa do padrão de deslocamentos dos medidores, como exemplificado na Figura 6. As situações onde a resultante dos movimentos em perfil e em planta situa-se abaixo da linha correspondente à inclinação original dos taludes caracterizam o movimento esperado dos taludes, não sugerindo indícios de problemas de instabilidade.

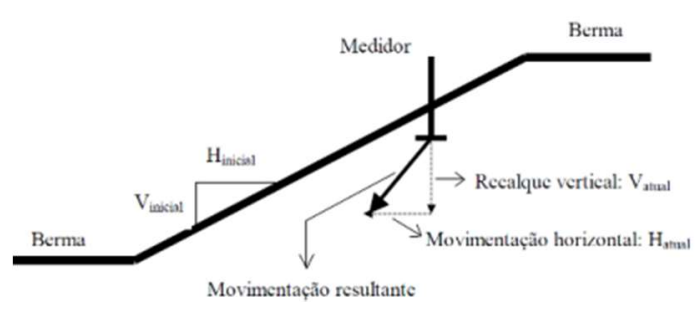

Figura 6 - Esquema de movimentação em perfil de medidor de recalques superficiais

No caso do aterro sanitário de Belo Horizonte, o monitoramento de recalques superficiais vem sendo realizado de forma sistemática desde o ano 2000 em um conjunto de aproximadamente 130 (centro e trinta) medidores. O monitoramento das movimentações em profundidade vem sendo realizado em um conjunto de 8 (oito) inclinômetros instalados no dique de partida, construído em solo compactado. A Figura 7 apresenta um exemplo de registros de um desses medidores de recalques superficiais. 


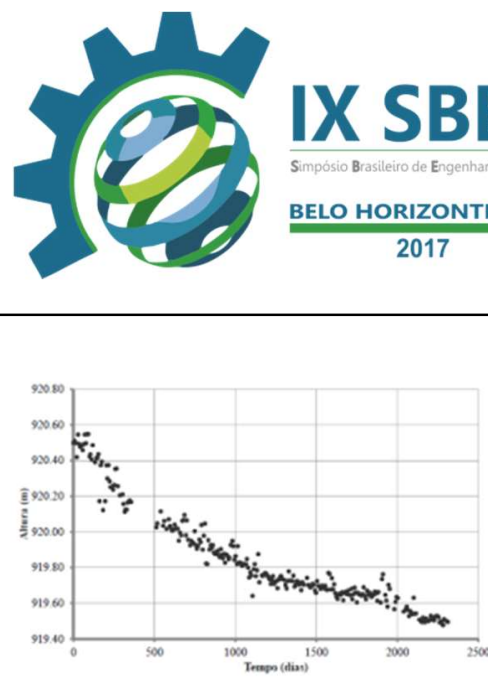

(a)

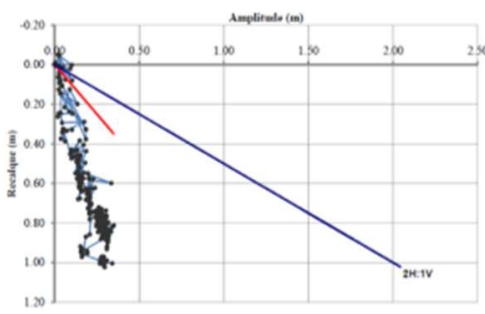

(b)

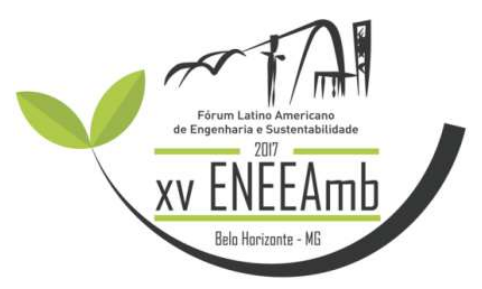

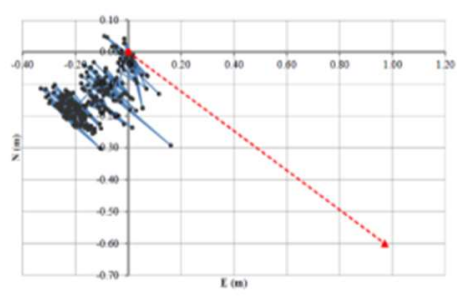

(c)

Figura 7 - Exemplo de registro do monitoramento de movimentações em superfície: a) Cotas do topo; b) Resultante em perfil das movimentações; c) Posição em planta.

\section{CONCLUSÕES}

Foram apresentados e discutidos alguns aspectos que comprovam a importância da presença contínua de equipes especializadas na realização de serviços topográficos nos aterros sanitários, em todas as fases, com destaque para as etapas de operação e monitoramento. Embora constituam um tipo de serviço usual em qualquer obra de infraestrutura, no caso dos aterros sanitários, devidos principalmente às características relacionadas à construção em etapas e à própria variabilidade e complexidade do comportamento geomecânico dos materiais dispostos (RSU, a contínua realização desses serviços é de extrema importância para a permanente avaliação das condições operacionais e da segurança ambiental e estrutural desses empreendimentos. Destaca-se que esses serviços topográficos devem ser realizados de forma criteriosa, regular e frequente, principalmente, em aterros sanitários de grande porte, como o de Belo Horizonte (MG).

\section{REFERÊNCIAS BIBLIOGRÁFICAS}

CATAPRETA, C. A.A., SIMÕES, G.F.; BATISTA, H. P. Monitoramento ambiental, operacional e geotécnico de aterros sanitários - a experiência do aterro sanitário de Belo Horizonte, MG. In: Congresso Brasileiro de Engenharia Sanitária e Ambiental, 24, Belo Horizonte. Anais...Rio de Janeiro: ABES, 2007.

CATAPRETA, C. A. A. Comportamento de um aterro sanitário experimental: avaliação da influência do projeto, construção e operação. Belo Horizonte, 337 p., 2008. Tese (Doutorado) -Universidade Federal de Minas Gerais.

LIMA, G. S., GUIMARÃES, L. T. Metodologia para seleção de áreas para implantação de aterro sanitário municipal. In: Congresso Brasileiro de Engenharia Sanitária e Ambiental, 21, João Pessoa, PB. Anais... Rio de Janeiro: ABES, 2001. 